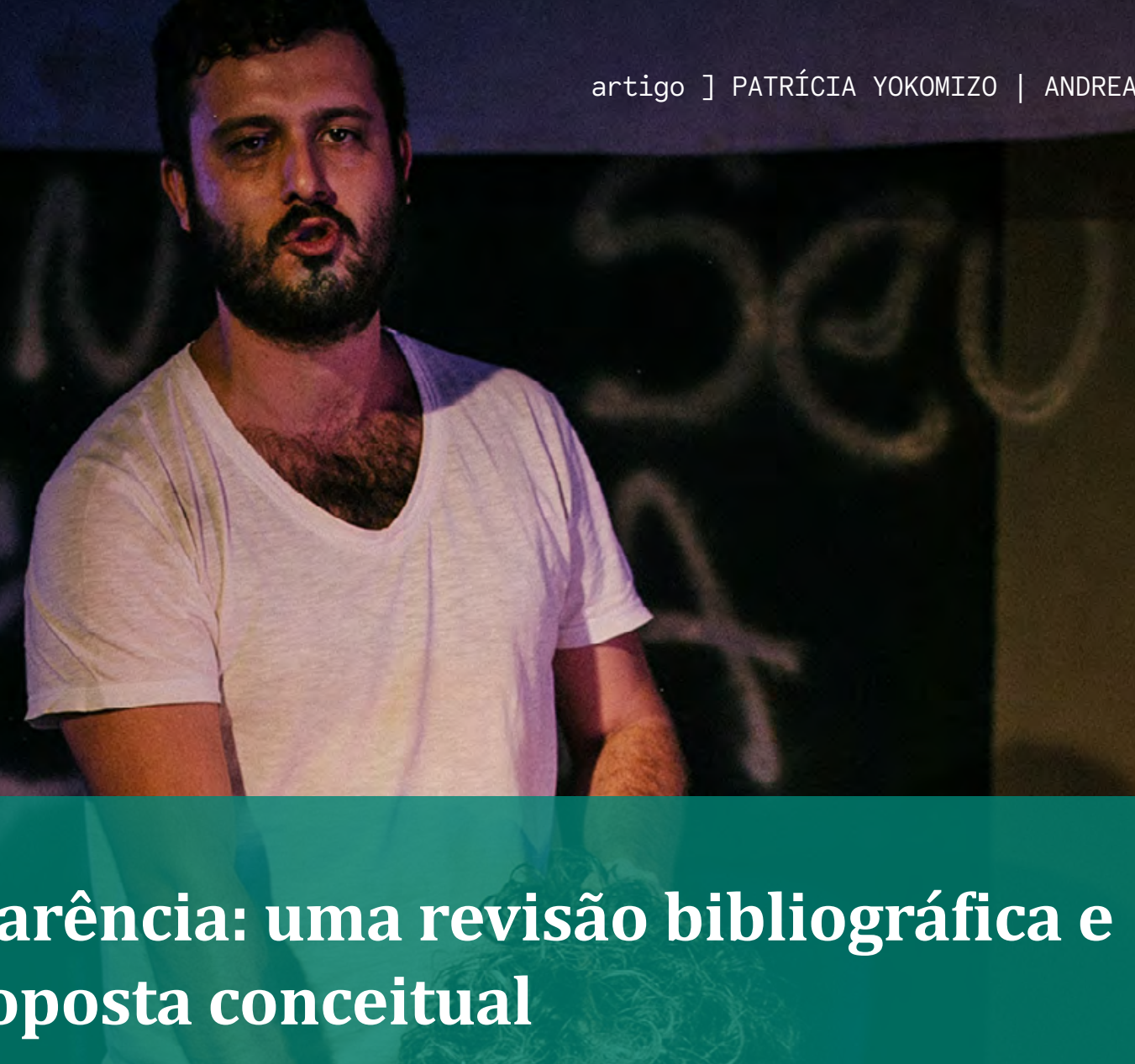

\title{
Aparência: uma revisão bibliográfica e proposta conceitual
}

Appearance: a literature review and conceptual proposal

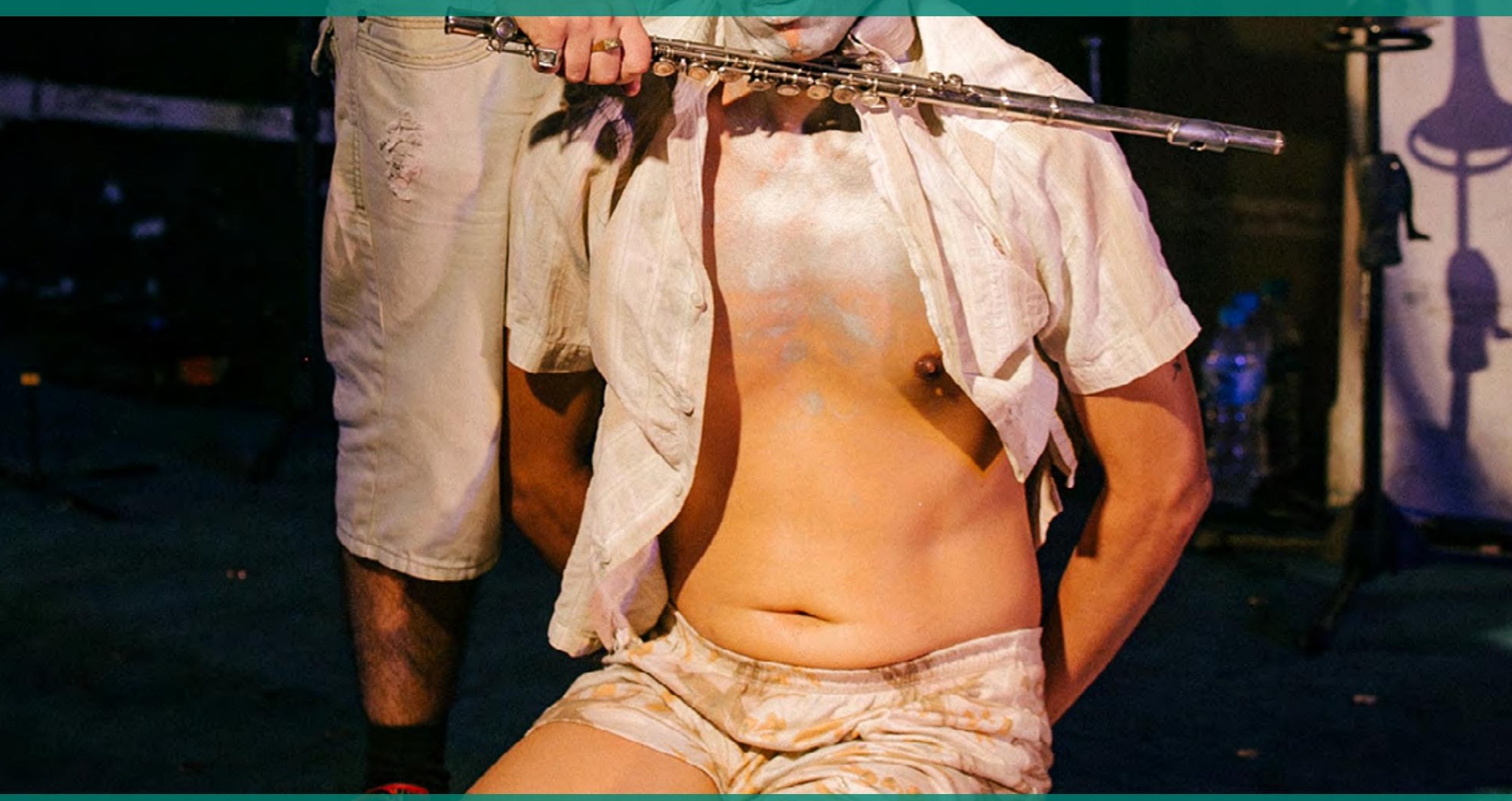




\section{PATRÍCIA DA SILVA YOKOMIZO1}

ORCID: http://orcid.org/0000-0001-9767-1596

\section{ANDREA LOPES ${ }^{2}$}

ORCID: http://orcid.org/0000-0002-7680-8618

[resumo] 0 artigo apresenta uma revisão bibliográfica sobre a noção de aparência e uma definição conceitual original, de natureza biopsicossocial, que procura contextualizar e sintetizar aspectos gerais da produção recente, em especial proveniente das Ciências Humanas. Observou-se a ausência de uma definição abrangente, integrada e clara de aparência, estando pulverizada em termos correlatos ou indireta e tangencialmente utilizada em diferentes estudos e campos do saber. Os esforços visaram fortalecer e congregar o debate sobre a construção da apresentação pessoal e coletiva em torno dessa variável, importante para a compreensão dos modos de vida e organização social ao longo do curso de vida.

\section{[palavras-chave] Aparência. Moda. Corpo. Beleza. Imagem.}

[abstract] The article introduces a literature review about the notion of appearance and presents an original conceptual definition, of a biopsychosocial nature, which seeks to contextualize and synthesize general aspects of the recent production on the subject, especially inside the Human Sciences field. There was a lack of a comprehensive, integrated and clear definition of appearance, which was sprayed in correlated terms or indirectly and tangentially used in different studies and fields of knowledge. These efforts aimed to strengthen and conjoin the debate about the construction of personal and collective presentation around this variable, important for the understanding of the ways of life and social organization along the life course.

[keywords] Appearance. Fashion. Body. Beauty. Image.

Recebido em: 30-01-2019.

Aprovado em: 22-03-2019.

\footnotetext{
1 Mestre em Gerontologia, Universidade de São Paulo. E-mail: pati@usp.br. Lattes: http://lattes.cnpq. br/2002114396935975.

2 Doutora em Educação, Universidade de São Paulo. E-mail: andrealopes@usp.br. Lattes: http://lattes. cnpq.br/1418645481026778.
} 


\section{Introdução}

O presente artigo tem como objetivo discutir a noção de aparência, a partir de revisão de literatura. Igualmente, propõe uma definição conceitual original para o termo, de natureza biopsicossocial. 0 estudo observou a ausência de um conceito claro e/ou abrangente no que tange à complexidade dessa variável, presente nos mais diferentes estudos obtidos. Percebeu-se, ainda, que muitos pesquisadores do período têm tratado o conceito de modo tangencial em estudos envolvendo principalmente as noções de corpo, beleza e imagem. A pulverização parece enfraquecer o debate e sua direção em torno de um consenso.

Os esforços fazem parte das ações do grupo de pesquisa, ensino e extensão Envelhecimento, Aparência e Significados (EAPS), da Escola de Artes, Ciências e Humanidades (EACH) da Universidade de São Paulo (Usp). O foco do grupo é especialmente investigar as variáveis socioculturais da aparência e seus significados ao longo do processo de envelhecimento. Desde sua fundação, em 2009, parte da noção de aparência como diferentes formas de construção da apresentação pessoal e coletiva. Busca promover a visibilidade e a importância da heterogeneidade desse tipo de experiência igualmente simbólica nos diversos contextos socioculturais. As ações do grupo ancoram-se, especialmente, na intersecção dos campos da Moda, da Antropologia e da Gerontologia.

Primeiramente, será apresentado o método utilizado. Em seguida, os resultados obtidos com a revisão bibliográfica, organizados em duas partes: uma síntese histórica envolvendo a noção de aparência, seguida de uma discussão sobre as principais contribuições levantadas quanto à compreensão e uso da noção. Por fim, apresenta-se o conceito de aparência, elaborado e aqui proposto pelo EAPS.

\section{Método}

O levantamento foi realizado em fontes brasileiras e internacionais, nas línguas portuguesa, inglesa e espanhola. Orientou-se pelo método da revisão narrativa, que trata de descrever e discutir de forma ampla a compreensão teórica de um determinado tema (ROTHER, 2007; GRANT \& BOOTH, 2009).

Investigou-se nove bases de dados e 15 periódicos, parte deles de caráter multidisciplinar. As fontes foram escolhidas conforme os campos de interesse do grupo e considerando-se o material disponível no acervo eletrônico da Usp, além das oportunidades de acesso gratuito disponíveis na internet. 0 escopo abrangeu o período de 2010 a 2017. Complementarmente, também foram consultadas publicações de posse do grupo, especialmente no que tange à reflexão preliminar histórica sobre o termo. 0 quadro 1 indica as fontes consultadas. 
QUADRO 1 - RELAÇ̃̃O DE BASES E PERIÓDICOS CONSULTADOS

\begin{tabular}{|c|c|c|}
\hline BASE DE DADOS & PERIÓDICOS BRASILEIROS & PERIÓDICOS INTERNACIONAIS \\
\hline $\begin{array}{ll}\text { - } & \text { Academic Search Premier } \\
\text { - } & \text { Ageline } \\
\text { - } & \text { JSTOR } \\
\text { - } & \text { Muse } \\
\text { - } & \text { Portal Capes } \\
\text { - } & \text { Pro Quest } \\
\text { - } & \text { Scielo } \\
\text { - } & \text { Scopus } \\
\end{array}$ & $\begin{array}{ll}\text { - } & 60 \text { e mais } \\
\text { - } & \text { Cadernos de Campo } \\
\text { - } & \text { Cadernos Pagu } \\
\text { - } & \text { Estudos Interdisciplinares sobre o } \\
& \text { Envelhecimento } \\
\text { - } & \text { Kairós Gerontologia } \\
\text { - } & \text { Revista Brasileira de Ciências do } \\
\text { - } & \text { Envelhecimento Humano } \\
\text { - } & \text { Gevista Brasileira de Geriatria e } \\
\text { - } & \text { Revista de Antropologia da Usp } \\
\text { - } & \text { Revista Dobros e Contextos } \\
\text { - } & \text { Revista Iara }\end{array}$ & $\begin{array}{ll}\text { - } & \text { Body \& Society } \\
\text { - } & \text { International Journal of Fashion } \\
\text { - Studies } \\
\text { - Journal of Fashion Marketing and } \\
\text { Management } \\
\text { - Journal of Spanish Cultural Studies }\end{array}$ \\
\hline
\end{tabular}

FONTE: Autoras, 2018.

Nas consultas realizadas, utilizou-se os descritores appearance, fashion, image, body e beauty, também no português (aparência, moda, imagem, corpo e beleza) e em espanhol (apariencia, moda, imagen, cuerpo e belleza). Considerando-se os interesses do EAPS, essas palavras iniciais foram combinadas aos seguintes termos, igualmente nas três línguas: 1) no campo gerontológico - idosos; sênior; idade; envelhecimento; velhice; longevidade; quarta idade; terceira idade; ageísmo; 2) no campo das Ciências Sociais - engajamento social; participação social; significativo; significado; engajamento social; participação social; 3) no campo da Educação - educação informal. A seleção dos descritores contou com o apoio das bibliotecárias da EACH-Usp, considerando-se as proposições presentes no vocabulário controlado organizado pela instituição.

A seleção do material teve como critério de inclusão o aparecimento dos descritores no título, resumo e palavras-chave. Quanto aos periódicos consultados, obteve-se um total de 67 artigos. Nas bases encontrou-se 7280 resultados de pesquisa. Porém, apesar do elevado número de materiais diversos listados, apenas 497 se mostraram relacionados à aparência, boa parte tangencialmente, em termos de apresentação pessoal ou coletiva, foco de interesse do grupo. Além disso, foram incorporadas na revisão outras 147 referências provenientes do banco de literatura do grupo, fruto da coleta de dados literários anteriores ou aquisições espontâneas.

Com relação às palavras-chave escolhidas, de modo geral foi possível encontrar uma pulverização de materiais e abordagens, advindos de diferentes campos. No entanto, a palavra aparência muitas vezes surgia como sinônimo de aparição. Também foram gerados muitos resultados relativos à fisionomia de objetos e alimentos. Notou-se que o termo aparência, no que diz respeito à apresentação pessoal e coletiva, não deteve um único conceito amplamente compreendido, denso, compartilhado ou debatido pela literatura consultada.

Sobre os tipos de estudo, foram encontradas pesquisas tanto quantitativas quanto de abordagem qualitativa. A maior parte trata sobre as mulheres, referindo-se aos temas esté- 
tica, imagem e corpo, sendo esse último o termo que mais gerou resultados. Com relação ao corpo, predominaram as publicações sobre questões médico-estéticas e psicológicas. Ainda, percebeu-se que os campos mais envolvidos e interessados por esse tipo de investigação foram os campos da Moda, da Psicologia, da Comunicação e das Ciências Sociais.

Ressalta-se, mais uma vez, que grande parte dos materiais foi selecionada por estabelecer algum tipo de relação com o foco do grupo e não necessariamente por abordar diretamente o termo aparência. Dessa maneira, não se trata aqui de apresentar uma revisão sistemática, mas apontar uma reflexão sobre os materiais obtidos de forma a propor um conceito que reúna e sintetize os debates e avanços identificados.

\section{Breve contextualização histórica sobre a noção de aparência na literatura consultada}

Historicamente, no geral, a revisão realizada apontou que autores de diferentes áreas do conhecimento têm estudado e produzido registros sobre o uso de vestes, calçados, penteados e adornos. Neste sentido, o contato com o material ainda permitiu observar e avançar na compreensão de que as vestes se encontram também relacionadas a posturas, expressões, cuidados pessoais, entre outros elementos de ordem física, estética, atitudinal, comportamental e simbólica. Os debates e estudos têm caracterizado os esforços em termos de apresentação social de indivíduos, grupos, sociedades e períodos históricos. A discussão, a seguir, visa ressaltar os detalhes dessas constatações.

Análises indicam que a organização de diversas sociedades recebe forte influência desse conjunto de aspectos, adotados como um meio de, principalmente: demonstrar origem ou pertencimento; representar uma ideia ou identidade; e distinguir-se. Em acréscimo, Calanca (2008) coloca que, ao longo do tempo, tais atributos têm servido aos indivíduos também para alcançar visibilidade e refletir o próprio cotidiano.

Köhler (2009), em um estudo bastante abrangente sobre a história do vestuário no mundo, organizou um registro acerca dos usos e transformações das vestimentas desde a Antiguidade até o final do século XIX. Durante o período, o autor descreve que as roupas, somadas a acessórios, calçados e penteados, eram usadas por diferentes povos e tribos, principalmente para diferenciar classes e etnias. Segundo o pesquisador, em distintas localidades as classes sociais superiores e inferiores costumavam usar trajes de formato muito semelhante, diferenciando-se, porém, pelos tipos de tecido, comprimentos e adornos empregados nas combinações.

Como exemplo, em relação aos assírios e babilônios, Köhler (2009) descreve que os homens de classes mais altas se diferenciavam dos demais usando vestes de comprimento até os pés e cintos enfeitados com borlas, sendo estas conferidas de acordo com sua dignidade. Em outro contexto, na Pérsia, os sacerdotes deveriam vestir branco no exercício de suas funções oficiais, sendo o corte de suas roupas o marcador da posição ocupada. 0 autor elucida ainda que, em arquivos históricos dos cretenses, as figuras de mulheres de classes inferiores estão vestidas apenas da cintura para baixo.

Essas e outras observações do estudo de Köhler (2009) apontam que, até a Idade Média (século V ao XV), o vestuário e demais complementos eram usados para formar e 
separar grupos sociais em termos de status, papéis, poder e influência. Outros marcadores, como os sexuais e de gênero, não foram muito relevantes e definidos até o século XVI, segundo o autor. Foi posteriormente a esse período que começaram a surgir diferenças mais marcantes entre homens e mulheres em termos de vestuário e outros elementos de seu aspecto visual, coexistindo à distinção de classes. Ainda de acordo com o pesquisador, até 1870 as mudanças nos trajes femininos estavam mais concentradas nos decotes, cintura, quadris e mangas, enquanto os masculinos alternavam entre comprimentos e uso de adornos como capas, cintos e gibões.

Segundo Mattos (2011), o período entre o final do século XIX e início do XX foi caracterizado por uma celebração da distinção social, cada vez mais reforçada nos modos de vestir. Existia, conforme a autora, um "prazer de ver" e "ser visto" (MATTOS, 2011, p. 163), de modo que o jeito de trajar e se portar tornava-se cada vez mais importante na esfera social, uma vez que entendido como instrumento de representação, afirmação e possível ascensão.

Em acréscimo, Blackman (2011) relata que o século XIX constituiu um domínio de quase 100 anos da chamada alta-costura (ou haute couture), modo de produção de vestuário e acessórios caracterizado pelo refinamento em termos de materiais, técnicas de confecção (muitas vezes completamente manuais) e estilo. Tais produções eram tomadas como referência por distintos grupos, superiores e inferiores, e eram elaboradas pelas casas de costura de Paris e Londres. Nestes termos, a produção da apresentação pessoal tomava tempo e era individualizada, cara e exclusiva.

Ainda segundo a autora, somente no final do século XIX, com a desvalorização dos preceitos burgueses e as consequências socioeconômicas dos conflitos mundiais da época, observou-se que o império da alta-costura começou a perder forças. Havia a necessidade de confeccionar peças de menor custo e em larga escala, empregando um novo conceito de vestir, que viria a facilitar o consumo de estratos sociais inferiores no século XX: o prêt-à-porter (ou pronto para usar). Este segue até os dias atuais entendido como uma tradução simplificada e mais barata das criações vistas em desfiles da haute couture. Comparativamente, a construção da apresentação pessoal passa a ser massificada, barateada, fugaz e descartável.

Para Crane (2006), enquanto a distinção de classes era bastante explícita nas vestimentas ao longo do século XIX na Europa e na América, em especial por meio do uso de uniformes e códigos de vestuário, no século XX a roupa e outros elementos da apresentação pessoal perdem gradativamente sua importância econômica - mas não a simbólica - com a propagação de peças prontas para usar e de variadas faixas de preço. Segundo a autora, a oferta de artigos mais baratos significava que aqueles cujos recursos eram limitados poderiam criar estilos pessoais e expressar sua identidade, ao invés de imitar estilos elaborados pelos mais ricos. Finalmente, a pesquisadora considera que o vestuário, desde os séculos XIX e XX, tem sido utilizado para refletir nossa ligação (ou não) com os demais indivíduos e grupos em sociedade, nas suas diferentes estruturas e instituições.

Em acréscimo, ainda sobre o século XX, Armstrong (2017) investigou os ideais construídos em torno da representação profissional de designers proposta por associações britânicas do setor entre 1945-1960. A autora observou que a percepção de superioridade ou inferioridade em relação a estes profissionais se dava por meio de suas roupas, vinculadas 
às atitudes e comportamentos esperados. Além disso, a apresentação dos estudantes de Design deveria discursar sobre a instituição da qual provinham. Estas organizações guiavam o mercado de trabalho e a opinião pública quanto às expectativas sobre o profissional da área. A pesquisadora aponta que a configuração, inserção e reconhecimento desses profissionais ocorria mais por suas escolhas de estilo de vida e comportamentos, que compreendiam vestuário e acessórios específicos, do que por seu conteúdo disciplinar ou expertise.

Nos registros sobre o universo da roupa e seus complementos, percebeu-se que a produção e uso desses itens têm servido, especialmente, para estratificar sociedades e identificar indivíduos. Tais funções ordenadoras têm se mantido presentes na concepção da apresentação pessoal em diferentes culturas, mesmo com mudanças ocorridas em termos de modelos, formatos e materiais.

Para Calanca (2008) e Blackman (2011), as mudanças em termos da maneira de vestir e de se portar se relacionam com as transformações ocorridas na concepção de tempo e espaço, implicando uma separação de trajes por ocasiões (uniforme de trabalho e roupa para o tempo livre, por exemplo) e lugares (praia, academia, rua etc.). Calanca considera também que as modificações nas vestimentas, atitudes e comportamentos têm ocorrido para distinguir não apenas momentos, locais, classes e gêneros, mas ainda sexualidade e papéis sociais em diversas civilizações.

Ainda de acordo com Calanca, as mudanças no modo de vestir e de se apresentar caracterizam o "fenômeno" denominado moda, que se entende como "um princípio constante, um hábito, uma exigência cultural" (CALANCA, 2008, p. 12). Para a autora, as modas são concebidas a partir dos costumes, crenças e regras de uma sociedade, refletindo - no caso, em roupas e adornos - padrões, preferências, estilos de vida e aspirações.

Em acréscimo, Blackman (2011) aponta que a moda é um fenômeno contínuo, explicando que as vivências do século XX serviram de base para formular o modo de vestir do início do século XXI. Para a pesquisadora, a maneira como nos apresentamos em sociedade ao longo das últimas décadas representa nossa compreensão sobre, principalmente: as consequências das guerras mundiais; os desastres ambientais e econômicos; os movimentos artísticos; a inovação no design; e a era digital, transformações advindas do século passado.

Nesse sentido, Crane (2006), baseada nas ideias de Fred Davis ${ }^{3}$, acrescenta que, no decorrer dos séculos XIX e XX, o vestuário era utilizado para expressar variados conflitos da estratificação social, tais como: juventude versus velhice; masculinidade versus feminilidade; androginia versus singularidade; trabalho versus diversão; conformismo versus rebeldia. Segundo a autora, o "fascínio da moda" (CRANE, 2006, p. 43) existente em diferentes sociedades ocorre justamente pela contínua redefinição das tensões sociais e dos estilos para expressá-las.

Para Blackman (2011), entre os séculos XX e XXI, a moda, em termos de vestuário e demais complementos, tem se mostrado dinâmica, mas não necessariamente democrática. Em outras palavras, a oferta, continuamente renovada, é bastante diversificada apenas para

\footnotetext{
3 DAVIS, Fred. Fashion, culture and identity. Chicago: University of Chicago Press, 1992.
} 
os que seguem os modelos vigentes de estilo e beleza. Ainda segundo a autora, em diferentes contextos sociais nota-se uma forte necessidade de autoexpressão e também uma demanda por novidades para distinguir-se - e, ao mesmo tempo, participar de um coletivo reconhecido.

Em complemento, Dweck (1999) descreveu que no Brasil o interesse pela moda, por artigos de vestuário e cosméticos nos anos 1990 estava principalmente relacionado com o âmbito profissional e cultural do período. De acordo com a pesquisadora, durante a referida década investia-se muito em produtos e serviços de beleza para participar do mercado de trabalho, ocupar uma determinada posição profissional e, ainda, combater as marcas do envelhecimento, vistas como prejuízos à apresentação pessoal.

Mais recentemente, uma pesquisa elaborada pelo Serviço de Proteção ao Crédito (SPC) e pela Confederação Nacional de Dirigentes Lojistas (CNDL) do Brasil, realizada com consumidores de todas as regiões brasileiras, de idade igual ou superior a 18 anos, homens e mulheres, de todas as classes econômicas, apresentou significados da beleza e motivos que levam pessoas a investir em artigos do setor. De acordo com o estudo, mais da metade dos participantes se diz vaidosa e considera que a beleza é uma necessidade para a vida social (SERVIÇO DE PROTEÇÃO AO CRÉDITO; CONFEDERAÇÃO NACIONAL DE DIRIGENTES LOJISTAS, 2016).

De acordo com o estudo do SPC e da CNDL, os consumidores analisados investem em produtos e serviços principalmente para o aumento da autoestima, seguido do desejo de ficar mais bonito e sentir-se atraente. A maioria dos entrevistados acredita que as pessoas bonitas são as que conseguem mais oportunidades na vida e alcançam sucesso nas relações amorosas, sendo essas crenças ainda maiores entre as classes C, D e E, de menor poder econômico no contexto brasileiro. Por fim, o modo como os demais notam a maneira como nos apresentamos é uma preocupação novamente maior entre as classes C, D e E.

Em complemento, sobre o âmbito político estadunidense de 2012, Ahler, Citrin, Dougal e Lenz (2017) apontam que roupas, expressões, posturas e outros elementos da apresentação pessoal influenciaram a escolha de eleitores quanto a distintos cargos de governo. De acordo com os pesquisadores, tais atributos foram ainda mais relevantes entre os públicos com menos nível de informação, os quais fundamentavam suas decisões mais no que o candidato aparentava do que em suas propostas substanciais.

Por outro lado, no universo profissional, o estudo de Baert (2017), realizado na Bélgica, indica que fotografias de perfis da rede social digital Facebook têm influenciado as decisões de recrutadores de recursos humanos. Na pesquisa, constatou-se que os candidatos com fotos entendidas como favoráveis por sua composição estética obtiveram mais oportunidades para entrevistas de emprego. As chances eram ainda mais elevadas quando combinadas à alta escolaridade.

As diferentes pesquisas consultadas apresentam, historicamente e em diferentes sociedades, um expressivo interesse dos indivíduos pelos modos de se apresentar e transmitir mensagens por meio de aspectos físicos, estéticos, simbólicos, comportamentais e atitudinais. Tais atributos têm sido utilizados especialmente para ocupar posições, exercer papéis, atender ou contrapor expectativas em distintas dinâmicas e contextos sociais. 0 conceito de aparência não é explícito e não detém contornos claros. No entanto, observa-se a existência 
da noção de apresentação pessoal e coletiva, em síntese, bastante vinculada ao debate sobre vestuário, atitudes, moda, significados, relações e ocupação de espaços e papéis, como também comunicação e expressão, mediante a combinação de uma diversidade de determinantes.

A seguir, são descritos os termos que, no levantamento realizado, comumente se associam à noção de aparência e auxiliam a compreensão da abrangência e complexidade dessa variável de investigação. Por fim, apresenta-se a proposta de conceito de aparência, fruto da revisão realizada e dos esforços do EAPS nestes dez anos de investigação sobre a temática envelhecimento, aparência e significados.

\section{A noção de aparência na literatura investigada: aspectos, associações comuns e pro- posta conceitual}

O levantamento realizado apontou que os termos corpo e a beleza são alguns dos temas correlatos mais presentes nas pesquisas consultadas que tratam da noção de aparência. 0 corpo é entendido como um dos instrumentos de performance da aparência (ARAÚJO; LEORATTO, 2013; COFFEY, 2013; GOLDENBERG, 2013; CASTILLO, 2014; CASTRO; PINTO, 2014; CAMPOS, 2015). Apreendeu-se que o corpo detém especial importância e sobrevalorização, sendo destacado e objeto de intervenção nos amplos universos do cinema, televisão, música, moda e publicitário. Neste último, mais especificamente nos anúncios de cosméticos, de produtos light, de dietas, cirurgias estéticas, entre outros. Em síntese, é apontado que o corpo vem a constituir, historicamente, um objeto de culto (CASTILLO, 2014).

Para Araújo e Leoratto (2013), até a primeira metade do século XX o vestuário era uma importante referência de poder. Ao longo dos tempos, segundo as autoras, ele foi despojado de sua posição pelo corpo, que, hoje, é visto como o elemento mais destacado na atribuição de status e diferenças entre as pessoas. A roupa passa a ser um item secundário, porém ao qual o corpo se submete e ajusta para melhor portar os modismos das épocas, de acordo com os pesquisadores.

Em complemento, Castillo (2014) aponta que as intenções do cultivo e cuidado do corpo sempre estão aliadas a algum momento histórico. O corpo está em constante "mutação e comunicação com o espaço e a sociedade cultural nos quais está inserido" (NOROGRANDO, 2014, p. 114). Monteleone, Witter e Gama (2015) descrevem, ainda, que o corpo veio a tornar-se um objeto de exposição regido por exigências de mercado e consumo de modelos.

Nesse sentido, Sant'Anna (2014) indica motivações gerais que impulsionaram o, segundo ela, vigente sucesso das cirurgias estéticas: a divulgação de um padrão de beleza global pela publicidade e o medo de envelhecer. Monteleone, Witter e Gama (2015, p. 926), que observaram a omissão de aspectos da velhice em imagens publicadas na revista Veja, descrevem que: "As doenças e incapacidades físicas próprias do declínio biológico do envelhecimento não correspondem às necessidades mercadológicas impulsionadas pela valorização do corpo perfeito e do ideal de beleza".

Já no final da década de 1990, Featherstone (1998) indicou que o corpo constitui um indicador de poder e prestígio social, base para julgamentos tanto de si como do outro, 
de forma que sua capacidade de operar no mundo social vem a ser medida pela cultura. 0 autor afirma também que a construção de identidade de um indivíduo depende, consideravelmente, da concepção de imagens do corpo.

Ainda sobre o corpo, também é encontrado em diversos estudos provenientes do levantamento o uso do termo imagem corporal (MONTEMURRO; GILLEN, 2013; VIANA; ANDRADE, 2013; NOROGRANDO, 2014). Este denomina-se, para Shkolnik e Iecovich (2013, p. 1718): "A soma de pensamentos, concepções, emoções e comportamentos que as pessoas têm sobre si mesmas [...] fortemente influenciada por normas sociais sobre a beleza física e atributos desejáveis para mulheres e homens".

A imagem corporal envolve a percepção, estima, satisfação, ansiedade e preocupação com o próprio corpo, sendo avaliada de acordo com a cultura e seus ideais de beleza, conforme Viana e Andrade (2013).

0 termo beleza, tal como o corpo, associa-se frequentemente aos estudos sobre aparência (SANT'ANNA, 2014; GUEVARA, 2015). Por meio de amplo levantamento, especialmente imagético, Umberto Eco (2014) elucida que, ao longo da história, a concepção sobre o bonito se mostra transitória e relacionada a determinantes como, por exemplo, cultura, religião e gênero. Segundo o autor, durante o século XX e em diante, nota-se a existência de um politeísmo da beleza, de modo que, principalmente após esse período, torna-se necessário revisar seu conceito com maior frequência.

Avelar e Veiga (2013) apontam que é comum a redução da beleza a traços físicos específicos, como a pele clara, olhos vivos, cabelos brilhantes etc. No entanto, segundo os autores, estas características marcam outros aspectos mais sutis, como juventude e resistência a doenças, "que comunicam sinais de saúde e potencial reprodutivo" (AVELAR; VEIGA, 2013, p. 339), além da capacidade de consumo.

Sant'Anna (2014) reuniu diversos entendimentos sobre a beleza formulados entre os séculos XIX e XX, sendo compreendida como: 1) direito de todas as classes e idades; 2 ) dever não apenas para sair de casa, mas permanente; 3) passaporte de primeiro mundo, que possibilita transpor fronteiras econômicas, culturais e de gênero; e 4) investimento no bem-estar individual e sucesso. Por outro lado, a autora coloca que, tendo em vista os predicados da beleza, a feiura veio a ser tratada como falta de sensibilidade e "coisa de gente ignorante" (SANT'ANNA, 2014, p. 184). No estudo de Teixeira, Freitas e Caminha (2014), os autores identificaram associações da beleza com a segurança, distinção social e formas de impulsionar a vida de um indivíduo.

Para Garcia (2008), do ponto de vista histórico a moda também se relaciona estreitamente à conferência de poder e à distinção social por meio da aparência, mediante a inclusão e valorização de itens que, ao longo de diferentes épocas, vêm servindo à assimilação ou incorporação de pessoas a um grupo social particular. Na história da beleza no Brasil, Sant’Anna (2014) aponta que os diversos elementos que elaboram a aparência têm sido utilizados para distinguir, por vezes pejorativamente, gêneros, classes sociais, ofícios e profissões, localidades e idades.

Dessa forma, grande parte da literatura levantada entende que o corpo, a beleza e a moda, como a aparência, são sociocultural e historicamente construídos. Atuam na visualização, aceitação, reflexo e perpetuação de modelos da educação, religião, profissão e outros 
contextos relacionados a um indivíduo em sociedade e à composição de sua aparência. Além disso, também ilustram o cuidado (ou a falta dele) no trato pessoal (COUTINHO; TOMAZETI; ACOSTA, 2013), apontando o potencial tanto de gestão da aparência (KWON; KWON, 2013), quanto de domínio e inserção nas relações sociais (CRANE, 2006; CAMPOS, 2015).

A revisão realizada indica ainda registros sobre as mudanças ou modas de vestuário, calçados, acessórios, penteados e cosméticos (KÖHLER, 2009; BLACKMAN, 2011), além de discussões sobre padrões de beleza (SANT'ANNA, 2014; CAMPOS, 2015) e uso desses atributos na organização de diferentes sociedades (CRANE, 2006; CALANCA, 2008). No entanto, notou-se a ausência de uma definição clara que congregue e explicite esse conjunto complexo de elementos em torno do que pode ser compreendido como apresentação pessoal e coletiva.

Em suas diferentes abordagens e campos, reuniu-se, em síntese, que o conceito de aparência deve abranger a combinação e utilização de atributos físicos, comportamentais, emocionais, atitudinais, estéticos e simbólicos, por parte de indivíduos e grupos sociais. Portanto, variáveis biopsicossociais.

Especialmente em estudos sobre beleza, corpo, imagem e identidade, encontrou-se algumas compreensões sobre o termo aparência. Entre os autores que trataram mais diretamente do conceito (CAVICO; MUFFLER; MUJTABA, 2013; KWON; KWON, 2013; KARL; PELUCHETTE; HALL, 2016), notou-se um consenso de que a aparência é um recurso de expressão individual e coletiva, que serve à organização social em distintos contextos culturais.

Para Silva (2013), a aparência pode ser entendida como uma referência visual dos indivíduos, que demonstram sua relação com o tempo e o espaço em que vivem por meio de roupas, acessórios, penteados, maquiagens etc. Silva, Cachioni e Lopes (2012, p. 240), ancoradas em Crane (2006), descrevem que a aparência "[...] vai muito além de roupas, indumentárias, incluindo também papéis, comportamentos e tarefas sociais [...] nos levando então a dizer que a aparência é socioculturalmente construída e que sofre influencias externas e internas".

Os elementos e dinâmicas mencionados pelas autoras podem ser configurados a partir de trocas simbólicas, comportamentais, atitudinais e afetivas. São, ainda, capazes de explicar sobre um indivíduo, sobre o meio em que este vive e sobre o modus operandi de seu envelhecimento.

Goffman (2002) descreve que um indivíduo elabora sua representação pessoal de acordo com o grupo e posição social a qual pertence, com vistas a exercer um papel e manter-se em uma rede de relações. Para tanto, o autor argumenta que é construída a denominada "fachada" (GOFFMAN, 2002, p. 29), que é composta por aspectos físicos, comportamentais, atitudinais e simbólicos, sendo responsável por situar os observadores do cotidiano em relação à apresentação do indivíduo. 0 pesquisador explica, ainda, que o reconhecimento do papel desempenhado se dá por meio do nível de coerência entre fachada, representação e contexto. Portanto, depende de um conjunto indissociável de características individuais e do entorno que são esperadas para certo personagem. A falta de coerência vem chamar atenção para as exceções, como, por exemplo: "O perfil de Roger Stevens (o verdadeiro agente imobiliário que maquinou a venda do Empire State Building) traçado pelo New Yorker faz 
comentários sobre o fato espantoso de Stevens ter uma casa pequena, um escritório pobre e nenhum papel timbrado" (GOFFMAN, 2002, p. 32).

0 trabalho de Goffman (2002), em síntese, elucida a relevância dos modos de aparentar visando inserção social e vice-versa. Em outras palavras, a aparência pode ser entendida pelo autor como uma das ferramentas para organização e envolvimento social, sendo influenciada pelas relações estabelecidas no cotidiano.

Em acréscimo, mais recentemente, Kwon e Kwon (2013) apresentam o termo gestão da aparência, utilizado para descrever o processo de engajamento de um consumidor mediante o uso de produtos e serviços de manutenção e controle da aparência. Para as autoras, cada indivíduo administra sua aparência baseado em múltiplos contextos e papéis que necessita desempenhar. Entendem o gerenciamento da aparência como uma prática cultural imbuída de significados e objetivos.

Nesse sentido, destacando seu caráter processual, o estudo sobre a história da beleza no Brasil desde o final do século XIX, de Sant'Anna (2014), aponta que durante a primeira metade do século XX, a construção da aparência esteve relacionada: 1) ao controle secreto da beleza feminina; 2) à não "exclusividade individual" dos corpos (SANT'ANNA, 2014, p. 56), que dependiam da aceitação e visibilidade social, inclusive para os homens; 3) à saúde, como significado de força para trabalhar; 4) e aos médicos e higienistas, como educadores informais que buscavam a construção de um povo belo e saudável. Já na segunda metade do período, ainda segundo a autora, tendo em vista especialmente a revelação na intimidade e a crescente exposição pública dos corpos, a oferta de produtos e tratamentos de beleza passou a promover transformações de caráter permanente na aparência. Além disso, a introdução de roupas mais reveladoras, como trajes de banho, de ginástica ou de comprimento mais curto, facilitou a valorização de cuidados para exibição cotidiana e também privada do corpo.

A partir das demais compreensões da literatura consultada (CAMPOS, 2015; SCHEMES; DUARTE; MAGALHÃES, 2015; GALAK; GRAY; ELBERT; STROHMINGER, 2016; KACZAN, 2016), percebeu-se ainda que a noção de aparência compõe um vasto repertório e campo de investigação. Observou-se serem diversos os aspectos envolvidos na gestão da vida em sociedade e do envelhecimento como processo dinâmico e heterogêneo, quando o foco é como a aparência é construída através dos tempos e mediante diferentes investimentos, acordos, punições, recompensas e expectativas.

Em síntese, a revisão indicou que a compreensão da aparência tem implicado uma (re)formulação contínua de variados aspectos, não apenas estéticos ou físicos, mas também comportamentais, atitudinais e simbólicos que, em conjunto, comunicam sobre um indivíduo ou grupo social. Historicamente, a aparência tem sido recurso fundamental para expressar posições, papéis e tarefas sociais em diferentes culturas. Percebe-se, ainda, uma estreita relação, mesmo que tangencial, da noção de aparência com outros termos, em especial corpo, vestuário, imagem e beleza. No entanto, não foi percebida a concepção da aparência como um conceito amplo, que abarque uma série de temas, no intuito de compreender, de forma mais integrada, a construção da apresentação pessoal e/ou coletiva.

Mediante a identificação das inúmeras contribuições dos autores discutidos até o momento, o EAPS, para efeito de seus trabalhos, define e propõe um conceito original de 
aparência, abarcando seus múltiplos domínios e estrutura, como sendo: um conjunto de aspectos físicos, comportamentais, atitudinais, estéticos e simbólicos construídos e externalizados pelos indivíduos ou grupos, compondo sua apresentação pessoal ou coletiva.

Diante da proposição desse conceito, o grupo entende que a aparência resulta do contato pessoal e coletivo com diversos contextos e relações socioculturais, historicamente datadas, estabelecidas ou não, ao longo da vida. Por meio da aparência, visa-se proteção e, especialmente, comunicar mensagens, significados, emoções, crenças, estilos e/ou tipos e compreensões de beleza. Além disso, expressa pertencimento, exercício de papéis e tarefas sociais, atendimento ou contraposição de expectativas e punições sociais reconhecidas e acordadas, muitas vezes, conforme a ocasião e o local, posto que ancoradas socioculturalmente e/ou em condições climáticas. Neste sentido, o EAPS considera, ainda, que a construção da aparência é processual, histórica, situacional, dinâmica, interdependente e heterogênea. Por fim, ocorre ao longo de toda vida e em acordo com as condições e modos por meio dos quais os indivíduos e os grupos envelhecem nesse percurso.

\section{Considerações finais}

A partir da revisão realizada, percebeu-se, primeiro, que poucos estudos têm definido ou trabalhado de modo incisivo a possível complexidade da variável aparência. Pesquisas, principalmente do campo da Moda, associadas, por vezes, à Comunicação, à Psicologia, à História e às Ciências Sociais, têm-se debruçado sobre a produção de registros sobre os modos e motivações do vestir entre determinados grupos e épocas, relacionando-se especialmente aos temas corpo, imagem e beleza.

No levantamento realizado notou-se também um consenso de que a construção da aparência tem servido à organização social. No entanto, pouco foi explorado em termos do conjunto de aspectos físicos, comportamentais, atitudinais, estéticos e simbólicos que se entende constituir a aparência, tratando de maneira difusa temas correlatos. 0 conceito de aparência e sua complexidade, tal como entendida pelo grupo, mostrou-se disperso, tangencial ou subentendido nas fontes consultadas.

Com base na bibliografia revisada e em pesquisas do grupo EAPS, propôs-se nesse artigo um conceito de aparência e seus desfechos, a fim de contribuir com futuras abordagens, não apenas científicas ou acadêmicas, mas também políticas, profissionais e comunitárias. Considera-se que a aparência é uma variável potente para compreender e explicar, mais do que estruturas sociais, igualmente modos de vida e de envelhecer, bem como seus significados. Além disso, é ainda relevante aos estudos sobre envolvimento ou isolamento social, uma vez que permite entender como são formulados, estabelecidos ou reconhecidos determinados modelos de visibilidade ou de exclusão social.

Destaca-se a necessidade de entender seu caráter biopsicossociocultural, recomendando-se que essa variável seja pensada tanto quanto possível de forma mais integral e interdisciplinar. Dessa forma, sugere-se que estudiosos utilizem fontes de pesquisas advindas de variadas áreas, complementando o conhecimento em torno do tema e desvendando a relação dos diferentes aspectos que resultam em determinada aparência e seus respectivos sentidos. 
Por fim, trata-se aqui de uma possível leitura e definição de aparência, útil às pesquisas que vem sendo desenvolvidas no âmbito do EAPS. Espera-se que incentive outros pesquisadores a elaborarem e a compartilharem novas contribuições sobre o estudo da aparência, inspirados nessa ou a partir dessa proposição e revisão de literatura. Mediante a complexidade temática, estudos devem combinar variáveis e contextos, visando uma noção mais assertiva da compreensão do assunto. No âmbito geral, os esforços visam que as pesquisas sobre aparência possam colaborar na indicação de caminhos salutares na compreensão sobre a heterogeneidade das formas de ser e de viver, como também de significar o curso de vida.

\section{Referências}

AHLER, Douglas J.; CITRIN, Jack; DOUGAL, Michael C.; LENZ, Gabriel. Face value? Experimental evidence that candidate appearance influences electoral choice. Political Behavior, v. 39, n. 1, p. 77-102, 2017. Disponível em: http://doi.org/10.1007/s11109-016-9348-6. Acesso em: 2 jul. 2019.

ARAÚJO, Denise Castilhos de; LEORATTO, Danielle. Alterações da silhueta feminina: a influência da moda. Revista Brasileira de Ciências do Esporte, v. 35, n. 3, p. 717-739, 2013. Disponível em: http://dx.doi.org/10.1590/S0101-32892013000300014. Acesso em: 2 jul. 2019.

ARMSTRONG, Leah. A new image for a new profession: self-image and representation in the professionalization of design in Britain, 1945-1960. Journal of Consumer Culture, p. 1-21, julho, 2017. Disponível em: http://doi.org/10.1177/1469540517708830. Acesso em: 2 jul. 2019.

AVELAR, Cátia Fabíola Parreira de;VEIGA, Ricardo Teixeira.Como entender a vaidadefeminina utilizando a autoestima e a personalidade. Revista de Administração de Empresas (FGVEAESP), v. 53, n. 4, p. 338-349, 2013. Disponível em: http://dx.doi.org/10.1590/S003475902013000400002. Acesso em: 2 jul. 2019.

BAERT, Stijn. Facebook profile picture appearance affects recruiters' first hiring decisions. New Media \& Society, v. 20, n. 3, p. 1220-1239, 2017. Disponível em: https://doi. org/10.1177/1461444816687294. Acesso em: 2 jul. 2019.

BLACKMAN, Cally. 100 anos de Moda. Tradução Mario Bresighello. São Paulo: Publifolha, 2011.

CALANCA, Daniela. História social da Moda. Tradução Renato Ambrosio. São Paulo: Editora SENAC São Paulo, 2008. 
CAMPOS, Raquel Discini. A educação do corpo feminino no Correio da Manhã (1901-1974): magreza, bom gosto e envelhecimento. Cadernos Pagu, v. 45, p. 457-478, 2015. Disponível em: http://dx.doi.org/10.1590/18094449201500450457. Acesso em: 2 jul. 2019.

CASTILLO, Enrique Gervilla. Desafíos de la belleza corporal. Valoración y crítica educativa. Revista Lusófona de Educação, v. 26, p. 29-43, 2014. Disponível em: http://revistas. ulusofona.pt/index.php/rleducacao/article/view/4704. Acesso em: 1 jul. 2019.

CASTRO, Ana Lúcia; PINTO, Renata Pires. Corporalidade brasileira na fabricação da identidade nacional. Ciências Sociais Unisinos, v. 50, n. 1, p. 34-40, 2014. Disponível em: 10.4013/csu.2014.50.1.04. Acesso em: 2 jul. 2019.

CAVICO, Frank J.; MUFFLER, Stephen C.; MUJTABA, Bahaudin G. Appearance discrimination in employment: legal and ethical implications of "lookism" and "lookphobia". Equality, Diversity and Inclusion International Journal, v. 32, n. 1, p. 83-119, 2013. Disponível em: https://doi.org/10.1108/02610151311305632. Acesso em: 2 jul. 2019.

COFFEY, Julia. Bodies, body work and gender: exploring a Deleuzian approach. Journal of Gender Studies, v. 22, n. 1, p. 3-16, 2013. Disponível em: http://doi.org/10.1080/0958923 6.2012.714076. Acesso em: 2 jul. 2019.

COUTINHO, Renato Xavier; TOMAZETI, Renata Venturini; ACOSTA, Marco Aurelio de Figueiredo. Representação de corpo na velhice: o corpo real versus o corpo social. Revista Kairós Gerontologia, v. 16, n. 4, p. 215-236, 2013. Disponível em: http://revistas.pucsp.br/ index.php/kairos/article/view/19665. Acesso em: 1 jul. 2019.

CRANE, Diana. A moda e seu papel social: classe, gênero e identidade das roupas. 2. ed. Tradução Cristiana Coimbra. São Paulo: Editora SENAC, 2006.

DWECK, Ruth Helena. A beleza como variável econômica: reflexo nos mercados de trabalho e de bens e serviços. Rio de Janeiro: Instituto de Pesquisa Econômica Aplicada, 1999.

ECO, Umberto. História da beleza. Tradução Eliana Aguiar. 4. ed. Rio de Janeiro: Record, 2014.

FEATHERSTONE, Mike. O curso da vida: corpo, cultura e imagens do processo de envelhecimento. In: DEBERT, Guita Grin (org.). Textos Didáticos no 13: Antropologia e Velhice. 2. ed. Campinas: Textos Didáticos, 1998. p. 45-64.

GALAK, Jeff; GRAY, Kurt; ELBERT, Igor; STROHMINGER, Nina. Trickle-down preferences: preferential conformity to high status peers in fashion choices. PLOS ONE, v. 11, n. 5, p. 1-11, 2016. Disponível em: http://doi.org/10.1371/journal.pone.0153448. Acesso em: 2 jul. 2019. 
GARCÍA, Alejandro Nestor. Distinção social e processo civilizador em Norbert Elias. Revista Iara, v. 1, n. 1, p. 68-101, 2008. Disponível em: http://www1.sp.senac.br/hotsites/blogs/ revistaiara/wp-content/uploads/2015/01/03_IARA_Garcia_versao-final.pdf. Acesso em: 1 jul. 2019.

GOFFMAN, Erving. A representação do eu na vida cotidiana. 10. ed. Tradução Editora Vozes Ltda. Petrópolis: Editora Vozes, 2002.

GOLDENBERG, Mirian. Corpo, gênero e envelhecimento na cultura brasileira. Revista A TerceiraIdade,v.24,n.58,p.69-81,2013.Disponível em: https://www.sescsp.org.br/online/ artigo/7304_CORPO+GENERO+E+ENVELHECIMENTO+NA+CULTURA+BRASILEIRA. Acesso em: 1 jul. 2019.

GRANT, Maria J.; BOOTH, Andrew. A typology of reviews: an analysis of 14 review types and associated methodologies. Health Information and Libraries Journal, v. 26, p. 91-108, 2009. Disponível em: https://doi.org/10.1111/j.1471-1842.2009.00848.x. Acesso em: 2 jul. 2019.

GUEVARA, Jordan. A conversation on beauty. Orientadora: Susan Sterner. 2015. Dissertação (Mestrado em Fotografia de Estúdio) - Columbian College of Arts and Sciences, George Washington Universit, Washington, D.C., 2015. Disponível em: http://scholarspace.library. gwu.edu/concern/gw_etds/m613mx652. Acesso em: 1 jul. 2019.

KACZAN, Gisela Paola. La práctica gimnástica y el deporte, la cultura física y el cuerpo bello en la historia de las mujeres. Argentina 1900-1930. Historia Critica, v. 61, p. 23-43, 2016. Disponível em: http://dx.doi.org/10.7440/histcrit61.2016.02. Acesso em: 2 jul. 2019.

KARL, Katherine; PELUCHETTE, Joy Van Eck; HALL, Leda McIntyre. Employee beliefs regarding the impact of unconventional appearance on customers in Mexico and Turkey. Employee Relations, v. 38, n. 2, p. 163-181, 2016. Disponível em: https://doi.org/10.1108/ ER-05-2015-0083. Acesso em: 2 jul. 2019.

KÖHLER, Carl. História do vestuário (1825-1876). 3. ed. Tradução Jefferson Luiz Camargo. São Paulo: Editora WMF Martins Fontes, 2009.

KWON, Yoo Ji; KWON, Kyoung-Nan. Multifaceted appearance management as cultural practice. Review of European Studies, v. 5, n. 4, p. 19-29, 2013. Disponível em: https://doi. org/10.5539/res.v5n4p19. Acesso em: 2 jul. 2019.

MATTOS, Maria de Fátima da Silva Costa Garcia de. Moda, imagem e representação. In: BONADIO, Maria Claudia; MATTOS, Maria de Fátima (org.). História e cultura de moda. São Paulo: Estação das Letras e Cores, 2011. p. 158-175. 
MONTELEONE, Thiago Vinicius; WITTER, Carla; GAMA, Eliane Florencio. Representação social de idosos: análise de imagens publicadas no discurso midiático. Estudos Interdisciplinares do Envelhecimento, v. 20, n. 3, p. 921-937, 2015. Disponível em: https://seer.ufrgs.br/RevEnvelhecer/article/view/48330. Acesso em: 1 jul. 2019.

MONTEMURRO, Beth; GILLEN, MeghanM.Wrinklesand saggingflesh: exploringtransformations in women's sexual body image. Journal of Women \& Aging, v. 25, p. 3-23, 2013. Disponível em: https://doi.org/10.1080/08952841.2012.720179. Acesso em: 2 jul. 2019.

NOROGRANDO, Rafaela. Imagem corporal: público, privado, superfície, âmago. Revista Iara, v. 7, n. 2,p. 113-133, 2014. Disponível em: http://www1.sp.senac.br/hotsites/blogs/revistaiara/ wp-content/uploads/2015/01/06_IARA_vol7_n2_Artigos.pdf. Acesso em: 1 jul. 2019.

ROTHER, Edna Terezinha. Revisão sistemática x Revisão narrativa. Acta Paulista de Enfermagem, v. 20, n. 2, p. v-vi, 2007. Disponível em: http://dx.doi.org/10.1590/S010321002007000200001. Acesso em: 2 jul. 2019.

SANT’ANNA, Denise Bernuzzi de. História da beleza no Brasil. São Paulo: Editora Contexto, 2014.

SCHEMES, Claudia; DUARTE, Paulo Henrique Saul; MAGALHÃES, Magna Lima. Anseios e desejos: mulher madura e a moda como construção social. Revista PRÂKSIS, v. 2, n. 12, p. 146-158, 2015. Disponível em: http://www.redalyc.org/articulo.oa?id=525552633014. Acesso em: 2 jul. 2019.

SERVIÇO DE PROTEÇÃO AO CRÉDITO; CONFEDERAÇÃO NACIONAL DE DIRIGENTES LOJISTAS. Significados da beleza: autoimagem e consumo. Brasil: Serviço de Proteção ao Crédito (SPC); Confederação Nacional de Dirigentes Lojistas (CNDL), julho, 2016.

SHKOLNIK, Darya; IECOVICH, Esther. Health, body image, gender and migration status: their relationship to sexuality in old age. International Psychogeriatrics, v. 25, n. 10, p. 1717-1727, 2013. Disponível em: https://doi.org/10.1017/S1041610213000604. Acesso em: 2 jul. 2019.

SILVA, Emanuelle Kelly Ribeira da. Moda, informação e cultura. Revista Iara, v. 6, n. 1, p. 66-89, 2013. Disponível em: http://www1.sp.senac.br/hotsites/blogs/revistaiara/wpcontent/uploads/2015/01/05_IARA_vol6_n1_Artigo.pdf. Disponível em: 1 jul. 2019.

SILVA, Natália Polo; CACHIONI, Meire; LOPES, Andrea. Velhice, imagem e aparência: a experiência de idosos da UNATI EACH-USP. Revista Kairós Gerontologia, v. 15, n. 7, p. 235257, 2012. Disponível em: https://revistas.pucsp.br/index.php/kairos/article/view/15251. Acesso em: 1 jul. 2019. 
TEIXEIRA, Fábio Luís Santos; FREITAS, Clara MariaSilvestre Monteiro de; CAMINHA,Iraquitan de Oliveira. A beleza feminina como poder: desvendando outros sentidos para a construção estética de si. Revista Brasileira de Ciências do Esporte, v. 36, n. 2, p. 485-500, 2014. Disponível em: http://www.scielo.br/pdf/rbce/v36n2/0101-3289-rbce-36-02-00485.pdf. Acesso em: 1 jul. 2019.

VIANA, Helena Brandão; ANDRADE, Jessica Souza Schlichting de. Fotografia e imagem corporal na maturidade. Revista Kairós Gerontologia, v. 16, n. 4, p. 103-123, 2013. Disponível em: https://revistas.pucsp.br/kairos/article/view/19632. Acesso em: 1 jul. 2019.

\section{Agradecimentos}

O presente artigo é parte de pesquisa realizada com apoio da Fundação de Amparo à Pesquisa do Estado de São Paulo (Fapesp). 